\title{
Review \\ Targeting PSMA Revolutionizes the Role of Nuclear Medicine in Diagnosis and Treatment of Prostate Cancer
}

\author{
Wietske I. Luining $1,2, *\left(\mathbb{C}\right.$, Matthijs C. F. Cysouw ${ }^{2}$, Dennie Meijer ${ }^{1,2}{ }^{(}$, N. Harry Hendrikse ${ }^{2}$, Ronald Boellaard ${ }^{2}{ }^{(0)}$, \\ André N. Vis ${ }^{1}$ and Daniela E. Oprea-Lager ${ }^{2}$ \\ 1 Department of Urology, Prostate Cancer Network Netherlands, Amsterdam University Medical Center, \\ VU University, 1081 HV Amsterdam, The Netherlands; d.meijer2@amsterdamumc.nl (D.M.); \\ a.vis@amsterdamumc.nl (A.N.V.) \\ 2 Department of Radiology and Nuclear Medicine, Cancer Center Amsterdam, Amsterdam University \\ Medical Center, Location VUmc, 1081 HV Amsterdam, The Netherlands; \\ m.cysouw@amsterdamumc.nl (M.C.F.C.); nh.hendrikse@amsterdamumc.nl (N.H.H.); \\ r.boellaard@amsterdamumc.nl (R.B.); d.oprea-lager@amsterdamumc.nl (D.E.O.-L.) \\ * Correspondence: w.i.luining@amsterdamumc.nl; Tel.: +31-20-4443289; Fax: +31-20-4446031
}

check for updates

Citation: Luining, W.I.; Cysouw, M.C.F.; Meijer, D.; Hendrikse, N.H.; Boellaard, R.; Vis, A.N.; Oprea-Lager, D.E. Targeting PSMA Revolutionizes the Role of Nuclear Medicine in Diagnosis and Treatment of Prostate Cancer. Cancers 2022, 14, 1169. https://doi.org/10.3390/ cancers14051169

Academic Editor: Kambiz Rahbar

Received: 11 February 2022

Accepted: 21 February 2022

Published: 24 February 2022

Publisher's Note: MDPI stays neutral with regard to jurisdictional claims in published maps and institutional affiliations.

Copyright: (c) 2022 by the authors. Licensee MDPI, Basel, Switzerland. This article is an open access article distributed under the terms and conditions of the Creative Commons Attribution (CC BY) license (https:// creativecommons.org/licenses/by/ $4.0 /)$.
Simple Summary: Imaging plays a crucial role in the accurate staging of prostate cancer. Prostatespecific membrane antigen (PSMA) is overexpressed in prostate cancer cells, and targeting the PSMA protein for diagnostic purposes has become of great clinical value. Another valuable feature of PSMA is its opportunity to serve as a target for delivering radionuclide therapy to cancer cells. PSMA-ligands can be labeled with various radionuclides, such as alpha and beta-emitters. This review offers an overview of the literature on recent developments in nuclear medicine regarding PSMA in prostate cancer diagnostics and targeted radionuclide therapy.

\begin{abstract}
Targeting the prostate-specific membrane antigen (PSMA) protein has become of great clinical value in prostate cancer (PCa) care. PSMA positron emission tomography/computed tomography $(\mathrm{PET} / \mathrm{CT})$ is increasingly used in initial staging and restaging at biochemical recurrence in patients with PCa, where it has shown superior detection rates compared to previous imaging modalities. Apart from targeting PSMA for diagnostic purposes, there is a growing interest in developing ligands to target the PSMA-protein for radioligand therapy (RLT). PSMA-based RLT is a novel treatment that couples a PSMA-antibody to (alpha or beta-emitting) radionuclide, such as Lutetium-177 $\left({ }^{177} \mathrm{Lu}\right)$, to deliver high radiation doses to tumor cells locally. Treatment with ${ }^{177} \mathrm{Lu}-\mathrm{PSMA}$ RLT has demonstrated a superior overall survival rate within randomized clinical trials as compared to routine clinical care in patients with metastatic castration-resistant prostate cancer (mCRPC). The current review provides an overview of the literature regarding recent developments in nuclear medicine related to PSMA-targeted PET imaging and Theranostics.
\end{abstract}

Keywords: prostate cancer; prostate-specific membrane antigen; PET/CT; Theranostics

\section{Introduction}

Prostate cancer (PCa) is the second-most common malignancy worldwide, and it is the fifth leading cause of cancer-related mortality among men [1]. When detected at an early stage, patients tend to have an excellent prognosis. However, the course of PCa is heterogeneous and varies from indolent to highly aggressive disease [2,3]. Therefore, accurate staging and risk stratification are essential in the management of patients with $\mathrm{PCa}$, given the wide variety of therapeutic options that may differ per disease stage.

Currently, imaging plays a pivotal role in assessing the disease extent, particularly through targeting the prostate-specific membrane antigen (PSMA) [4]. PSMA is a transmembrane glycoprotein substantially overexpressed in malignant prostate cells [5]. As 
a result, PSMA is an attractive target for molecular imaging with positron emission tomography (PET) using one of several available radiolabeled PSMA-ligands. However, the expression of PSMA is not restricted to prostate (cancer) cells only and may be found in several non-prostatic diseases [5,6]. In clinical practice, the main indications to perform PSMA PET/computed tomography (CT) are initial staging and restaging at the biochemical recurrence of disease after treatment with curative intent $[3,7,8]$. Recently, the E-PSMA reporting guidelines have been proposed in order to harmonize protocols and to standardize PSMA PET/CT imaging reporting in PCa [9].

Aside from targeting the PSMA protein for diagnostic purposes, there is an increasing interest in using PSMA-radioligands for therapeutic purposes. This approach is called radioligand therapy (RLT). PSMA-RLT combines PSMA-ligands and therapeutic radionuclides to deliver targeted high radiation doses to cancer cells, leading to cellular death. PSMAligands can be labeled with either alpha (e.g., Actinium-225 ( ${ }^{225}$ Ac), Lead-212) or betaemitting radionuclides (e.g., Lutetium-177 $\left.\left({ }^{177} \mathrm{Lu}\right)\right)$, with both having different characteristics in terms of physics and radiobiology [10]. Most experience has been gained with ${ }^{177} \mathrm{Lu}$ PSMA-617 in patients with metastatic castration-resistant prostate cancer (mCRPC) [11,12]. In the VISION trial, treatment with ${ }^{177}$ Lu-PSMA-617 resulted in an overall survival (OS) benefit of 4 months compared to routine clinical care [12].

This review summarizes the current literature on the recent developments in nuclear medicine regarding PSMA in PCa diagnostics and targeted radionuclide therapy.

\section{Prostate Cancer}

\subsection{Prostate Cancer Diagnosis}

PCa suspicion rises with an abnormal digital rectal examination (DRE), an elevated serum prostate-specific antigen (PSA)-value, or both. However, PSA is organ-specific, not PCa specific, and might be increased in patients with benign diseases (i.e., prostatitis or benign prostate hyperplasia). Consequently, histopathological tissue assessment of prostate biopsies is required to confirm the diagnosis and estimate its aggressiveness, classified using the Gleason score (GS) [13]. Nevertheless, prostate biopsies are vulnerable to sampling errors, leading to false-negative outcomes and potentially inaccurate tumor evaluation [14]. Therefore, current international guidelines recommend multiparametric magnetic resonance imaging (mpMRI) in patients with an elevated PSA before prostate biopsy, allowing the targeted biopsy of suspicious radiological lesions [3]. Additionally, MRI provides essential information for local staging and planning of curative treatment, such as radical prostatectomy or radiation therapy [3]. Recently, the use of PSMA PET/CT for the initial staging of patients with high-risk PCa has also been recognized based on the results of several prospective studies $[15,16]$.

\subsection{Risk-Stratification and Local Tumor Staging}

According to the International Society of Urological Pathology (ISUP) 2014, grading systems based on the GS, prostate biopsies are classified into five different grades groups of malignancy, ranging from 1 to 5 [13]. Alongside, the Tumor-Node-Metastasis (TNM) classification system is utilized for the uniform staging of PCa [17]. PCa is classified as an organ-confined (T1 and T2) or locally advanced disease (T3 and T4), the latter indicating that the tumor extends beyond the prostate and may invade adjacent structures. These clinical parameters (i.e., TNM stage, PSA, and ISUP grade) are implemented in the European Association of Urology (EAU) PCa risk categories, dividing patients into low, intermediate, or high-risk disease groups [3]. Higher risk groups are associated with an increased risk of having or developing metastatic disease. This underlines the essence of correct and complete staging in these patients, including assessment of metastatic dissemination.

\subsection{Staging of Metastases in Prostate Cancer}

The assessment of regional lymph node metastases (N-status) and distant metastases (M-status) is crucial for the accurate staging of patients with PCa since it affects therapy 
planning and prognosis. Unfortunately, the median survival of men with newly diagnosed metastatic (M1) PCa is approximately 42 months [18]. Common metastatic sites are local and/or distal lymph nodes and bone, while visceral metastases occur less frequently. According to the EAU guidelines, metastasis screening at initial diagnosis is recommended in intermediate and high-risk disease by at least abdominopelvic imaging and bone scintigraphy (BS) [3]. However, the diagnostic accuracy of these conventional imaging modalities is limited for detecting PCa lesions [19,20]. For example, the sensitivity of CT and MRI for pelvic lymph node detection is only $42 \%$ and $39 \%$, respectively [19]. A potential explanation may be that these imaging modalities primarily rely upon lesion morphology (i.e., the shape and size of a lesion) for detection, which might be inaccurate in (early) metastatic PCa with small metastases being missed.

\section{PSMA PET Diagnostics}

Radiolabeled PSMA-ligands have recently been introduced to the rapidly evolving nuclear imaging field. While most studies have investigated its performance in either primary staging or restaging at biochemical recurrence (e.g., rising PSA after local therapy), there is increasing data regarding its use in the follow-up of patients with mCRPC. PSMAligands can be labeled with ${ }^{68}$ Gallium $\left({ }^{68} \mathrm{Ga}\right)$ or ${ }^{18}$ Fluoride $\left({ }^{18} \mathrm{~F}\right) .{ }^{18} \mathrm{~F}$-labeled tracers have increased positron yield and shorter positron range compared with ${ }^{68} \mathrm{Ga}$-labeled tracers, resulting in a higher resolution of the images, with potentially enhanced detection of (small) metastases. Additionally, ${ }^{18} \mathrm{~F}$ has the advantages of a longer half-life (110 versus $68 \mathrm{~min}$ for ${ }^{68} \mathrm{Ga}$ ), enabling centralized production on a larger scale [21]. ${ }^{68} \mathrm{Ga}-\mathrm{PSMA}-11$ and ${ }^{18}$ F-DCFPyL are the most commonly used radioligands and are primarily excreted by the urinary tract, often making the interpretation of the prostate bed and/or metastases adjacent to the ureters challenging [4,22]. A relatively novel introduced ${ }^{18} \mathrm{~F}$-labeled tracer is ${ }^{18}$ F-PSMA-1007, with a comparable diagnostic accuracy as ${ }^{68} \mathrm{Ga}-\mathrm{PSMA}-11$ and ${ }^{18} \mathrm{~F}-\mathrm{DCFPyL}$ for detecting the local recurrence of PCa in the prostatic fossa [23-26]. The ${ }^{18} \mathrm{~F}-\mathrm{PSMA}-$ 1007 excretion pathway is mainly by the hepatobiliary tract and marginally by urinary excretion, yielding the potential benefit to differentiate nodal metastases or local recurrence from physiological urinary activity [23,24,27]. A disadvantage of ${ }^{18}$ F-PSMA-1007 is its high unspecific bone uptake, leading to a greater prevalence of positive PSMA findings attributed to a benign origin. Therefore, extensive reader training is necessary to become familiar with the interpretation and reporting $[25,26]$. Implementing the recently developed E-PSMA criteria might mitigate these clinically relevant interpretation differences among readers in routine daily practice [9].

\subsection{Initial Staging}

Recent studies have demonstrated the advantages of PSMA PET/CT in the primary staging of men with PCa compared to conventional imaging modalities $[8,16,19,20,28]$. For example, Pienta et al. evaluated the performance of ${ }^{18} \mathrm{~F}-\mathrm{DCFPyL}$, a second-generation PSMA-ligand PET/CT, in detecting metastatic disease at initial staging in high-risk PCa compared with histopathology in the OSPREY trial. In this prospective multicenter phase II/III trial, a total of 252 patients with high-risk PCa planned for radical prostatectomy with lymph node dissection were included. ${ }^{18} \mathrm{~F}$-DCFPyL PET/CT compared to CT or MRI alone showed higher specificity (97.9\% versus $65.1 \%$, respectively), positive predictive value (PPV) (86.7\% versus $28.3 \%$, respectively), and negative predictive value (NPV) $(83.2 \%$ versus $77.8 \%$, respectively), with similar sensitivity ( $40.3 \%$ versus $42.6 \%$, respectively) for the detection of pelvic lymph node involvement (LNI) [8]. Similar results were found when investigating the diagnostic accuracy of ${ }^{68} \mathrm{Ga}$-PSMA and ${ }^{18}$ F-DCFPyL PET/CT for lymphnode staging in primary PCa $[29,30]$. The prospective cohort study by van Kalmthout et al. reported a limited sensitivity (41.5\%) and high specificity (90.9\%) for detecting pelvic lymph node metastases with ${ }^{68} \mathrm{Ga}$-PSMA PET/CT in patients with newly diagnosed PCa [30]. A similar study from Jansen et al. reported a sensitivity and specificity of $41.2 \%$ and $94.0 \%$, respectively, for detecting lymph node metastases with ${ }^{18} \mathrm{~F}-\mathrm{DCFPyL}$ PET/CT [29]. 
Nevertheless, mainly based on the encouraging results from the 'proPSMA' trial, the European Association of Urology (EAU) guidelines have recently incorporated PSMA PET/CT for initial staging purposes [3]. In this prospective multi-center study, 302 patients with high-risk PCa, prior to curative-intent surgery or radiotherapy, were randomly assigned to conventional imaging with $\mathrm{CT}$ and bone scintigraphy or ${ }^{68} \mathrm{Ga}-\mathrm{PSMA}-11 \mathrm{PET} / \mathrm{CT}$. The accuracy of ${ }^{68} \mathrm{Ga}$-PSMA PET/CT was $27 \%$ higher than that of CT and bone scintigraphy $(92 \%$ versus $65 \% ; p<0.0001)$. Conventional imaging had a lower sensitivity $(38 \%$ versus $85 \%$ ) and specificity (91\% versus $98 \%$ ) than PSMA PET/CT. Moreover, the ${ }^{68}$ Ga-PSMA $\mathrm{PET} / \mathrm{CT}$ scan induced management change more frequently than conventional imaging, with less equivocal findings and lower radiation exposure [16].

A PSMA PET/CT limitation is that a negative PSMA PET/CT cannot rule out lymph node metastases [8,29-31]. Consequently, the ePLND remains the gold standard for primary nodal staging, despite known potential complications, such as lymphocele, lymphedema, and deep venous thrombosis [3].

\subsection{Biochemical Persistence}

In $5-20 \%$ of the patients treated with radical prostatectomy (RP), the PSA level remains measurable after treatment [32,33]. Biochemical persistence (BCP) is defined as a detectable PSA level of $\geq 0.1 \mathrm{ng} / \mathrm{mL}$ within 4-6 after RP [34]. Causes of BCP are the presence of (micro)metastases or residual disease in the prostatic tissue. Unfortunately, BCP is associated with more advanced $\mathrm{PCa}$, such as higher pathological tumor stages, higher ISUP grade, positive surgical margins, and an impaired prognosis $[33,35,36]$. Schmidt-Hegemann et al. more frequently observed pelvic LNI on ${ }^{68} \mathrm{Ga}$-PSMA PET/CT in patients with BCP than patients who develop biochemical recurrence [37]. The multicenter retrospective study by Farolfi et al. reported that ${ }^{68} \mathrm{Ga}-\mathrm{PSMA} \mathrm{PET} / \mathrm{CT}$ localized PCa in two-thirds of the patients with BCP [38]. Additionally, Meijer et al. analyzed the findings of ${ }^{68} \mathrm{Ga}-\mathrm{PSMA}$ PET/CT and ${ }^{18}$ F-DCFPyL PET in 150 patients with BCP after surgical treatment. They found PSMA positive lesions outside the prostatic fossa in $67 \%$ of the patients and in $26 \%$ of patients outside the pelvis [39]. Therefore, accurate localization of residual disease with PSMA $\mathrm{PET} / \mathrm{CT}$ is critical to determine and guide the most effective treatment.

\subsection{Restaging at Biochemical Recurrence}

PSMA PET/CT has been extensively evaluated in patients with biochemically recurrent disease (BCR) after definite treatment. $B C R$ is defined as a serum PSA of $\geq 0.2 \mathrm{ng} / \mathrm{mL}$ after radical prostatectomy or a serum PSA $\geq 2.0 \mathrm{ng} / \mathrm{mL}$ above the nadir after radiation therapy $[40,41]$. In patients with $B C R$, identifying the recurrence site is crucial as it directly influences therapeutic decision-making. The detection of metastatic disease is strongly associated with the level of PSA-values when performing the PSMA PET/CT [7,28,42]. Interestingly, Jansen et al. analyzed PSMA PET/CT performed in 63 patients with low PSA levels $(<2.0 \mathrm{ng} / \mathrm{mL}$, not meeting BCR criteria) after curative radiotherapy and found PSMA positive lesions in 53/63 patients (84.1\%) defined as local recurrence (21 patients) or metastatic disease (32 patients) [43]. Perera et al. reported sensitivities for ${ }^{68}$ Ga-PSMA PET /CT in detecting BCR of $33 \%, 45 \%, 59 \%, 75 \%$, and $95 \%$ for PSA ranges of $<0.2,0.2-0.49$, $0.5-0.99,1.0-1.99$, and $\geq 2.0 \mathrm{ng} / \mathrm{mL}$, respectively [28].

Before the introduction of PSMA PET, prostate cancer molecular imaging was commonly performed using radiolabeled choline-ligands (e.g., ${ }^{11} \mathrm{C}$-choline and ${ }^{18} \mathrm{~F}$-choline) and more recently ${ }^{18} \mathrm{~F}$-Fluciclovine [15,44-47]. In the literature, ${ }^{68} \mathrm{Ga}$-PSMA PET /CT has demonstrated higher detection rates than ${ }^{11} \mathrm{C}$-Choline PET/CT in BCR, especially in patients with low PSA levels [44-48]. A recent prospective trial by Calais et al. enrolled 50 patients with BCR after RP with low a PSA level $(<2.0 \mathrm{ng} / \mathrm{mL})$ to compare the detection rate and reproducibility of ${ }^{68} \mathrm{Ga}$-PSMA PET/CT versus ${ }^{18} \mathrm{~F}$-Fluciclovine. They found significantly higher detection rates with ${ }^{68} \mathrm{Ga}$-PSMA PET/CT compared to ${ }^{18} \mathrm{~F}$-Fluciclovine ( $56 \%$ versus $26 \%$; OR $4.895 \%$ CI: $1.6-19.2, p=0.0026$ ), also when stratified by PSA level (PSA $<0.5 \mathrm{ng} / \mathrm{mL}: 46 \%$ versus $27 \%$; PSA $0.5-1.00 \mathrm{ng} / \mathrm{mL}$ : $67 \%$ versus $28 \%$; PSA $1.01-2.00$ : 
$67 \%$ versus $17 \%$, respectively) [15]. Furthermore, the recent prospective, phase III CONDOR trial by Morris et al. assessed the diagnostic performance of ${ }^{18} \mathrm{~F}$-DCFPyL in patients with BCR with negative or equivocal findings on PET/CT ( ${ }^{18} \mathrm{~F}$-Fluciclovine or ${ }^{11} \mathrm{C}$-Choline $)$ or conventional imaging (CT, MRI, or BS). Improved detection rates were found when PSA levels were higher (PSA < $0.5 \mathrm{ng} / \mathrm{mL}$ : 36.2\%; PSA 0.5-0.99 ng/mL: 51.4\%; PSA 1.0-1.99: $66.7 \%)$. A high correct localization rate (84.8-87.0\% lower bound of 95\%CI: 77.8-80.4) was found. Furthermore, disease management was changed in nearly two-thirds of the analyzed patients $(63.9 \%, n=131)$ [7].

Apart for cohort A of the phase 2/3 OSPREY trial, cohort B included patients with suspected locoregional recurrence and/or distant metastatic disease on conventional imaging (CT, MRI, or BS). Among all patients, high median sensitivity (95.8\%) and PPV (81.9\%) of ${ }^{18}$ F-DCFPyL PET/CT were found for detecting recurrence or metastatic disease, respectively. Moreover, metastatic disease was described in $57.6 \%$ of the patients previously staged with locoregional disease on conventional imaging. The sensitivity ranged from $88.9 \%$ to $100 \%$ and the PPV from $61.5 \%$ to $88.9 \%$ in patients with low PSA levels $(<2.0 \mathrm{ng} / \mathrm{mL})$ [8]. Considering these superior detection rates of PSMA PET/CT on biochemical recurrence of disease, PSMA PET/CT has become the recommended imaging modality for BCR following previous curative-intent therapy (Figure 1) [3].
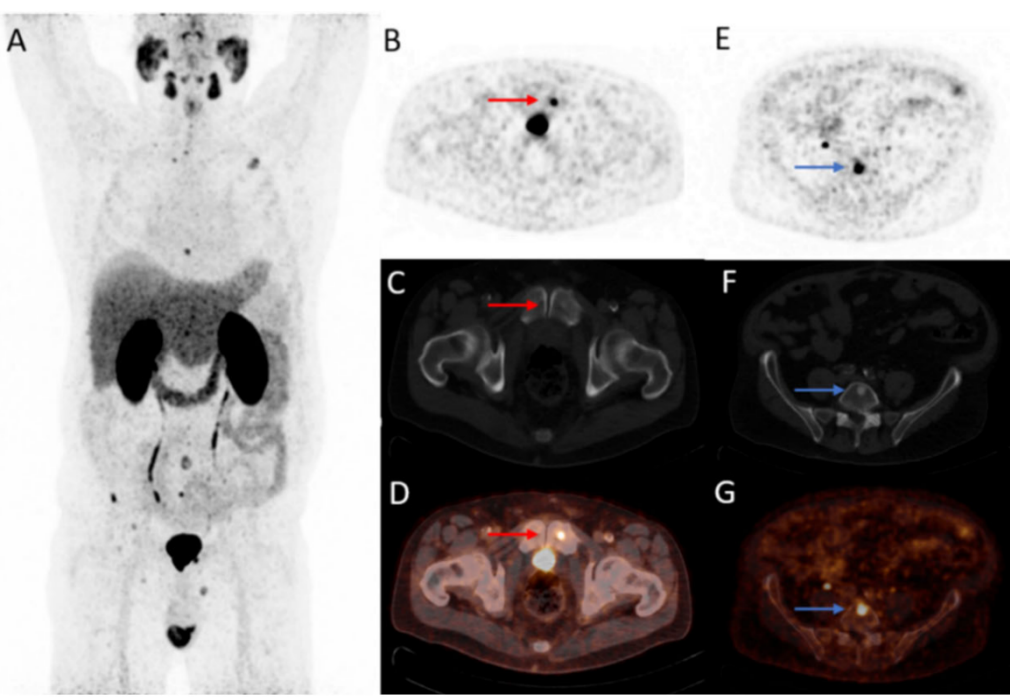

F



Figure 1. A 70-year-old patient with biochemical recurrence after radical prostatectomy (Gleason $3+4=7$, PSA-nadir $<0.1 \mathrm{ng} / \mathrm{mL}$ ) with a PSA of $0.7 \mathrm{ng} / \mathrm{mL}$ at the PET/CT scan time. Restaging ${ }^{18} \mathrm{~F}-$ DCFPyL PET/CT detected multiple bone metastases $(>10)$ at low serum PSA value $((\mathbf{A})$; maximum intensity projection). Transversal ${ }^{18} \mathrm{~F}-\mathrm{DCFPyL}$ PET $(\mathbf{B}, \mathbf{E})$ and fused PET/CT $(\mathbf{D}, \mathbf{G})$ images illustrate two bone metastases (os pubis left, red arrow: $\mathrm{SUV}_{\max }$ : 9.76; L5 vertebra, blue arrow $\mathrm{SUV}_{\max }$ : 8.02) with sclerotic substrate on CT $(\mathbf{C}, \mathbf{F}, \mathbf{H})$.

PSMA PET/CT is increasingly used to select the optimal treatment strategy in patients with BCR, and PSMA PET findings frequently result in management changes [49-51]. For example, Meijer et al. found a change of preferred management in $40.7 \%$ of the patients with BCR who underwent ${ }^{18}$ F-DCFPyL PET/CT for restaging after curative-intent treatment [50]. Likewise, Calais et al. assessed the impact of ${ }^{68} \mathrm{Ga}$-PSMA PET/CT on the treatment plan of BCR and showed a change of management in 53\% of the patients [49].

When PCa recurrence is restricted to the prostatic fossa, salvage radiation therapy (SRT) may be considered as a potentially curative treatment option and proves to be the most effective at a PSA value of $\leq 0.5 \mathrm{ng} / \mathrm{mL}$ [34]. However, the findings on PSMA PET/CT before SRT impact the planned treatment by extending the target volume, implying dose escalations, or refraining from radiotherapy [52-54]. Since the introduction of PSMA PET/CT, patients with BCR may be diagnosed as having metastatic disease at an earlier stage, also 
known as 'stage migration'. Patients with the oligometastatic disease have a limited number of metastases (usually defined as 1-5 metastatic lesions). Metastasis-directed radiotherapy (MDT) on these lesions may postpone the initiation of systemic treatment [55-57]. A phase II randomized clinical trial by Philips et al. compared stereotactic body radiation therapy (SBRT) observation in patients with oligometastatic recurrent PCa (up to three metastases) on conventional imaging. ${ }^{18} \mathrm{~F}$-DCFPyL PET/CT was performed at baseline in the patients receiving SBRT, and these results were blinded to the investigative team during therapy planning. A higher number of patients progressed at six months in the observational cohort than into the group allocated to SBRT (61\% versus 19\%). The SBRT treatment plan was compared to the results of the PSMA PET/CT, and patients were divided into a total and subtotal consolidation of PSMA avid lesions. Total consolidation of PSMA lesions decreased the risk of new lesions at six months (16\% versus $63 \%$ ) [57]. This study highlights the impact of PSMA PET/CT in planning MDT in patients with oligometastatic disease. However, the long-term effect on overall survival and quality of life are still to be demonstrated.

\subsection{Castration-Resistant Prostate Cancer}

Castration-resistant prostate cancer (CRPC) is defined as biochemical or radiological progression of disease on conventional imaging in the presence of castration levels of serum testosterone (i.e., $<50 \mathrm{ng} / \mathrm{dL}$ ) [34,58]. In CRPC, the number of available therapeutic choices has increased, while the optimal treatment strategy is not fully established [34,59-63]. Current guidelines (PCWG3 and EAU) recommend conventional imaging in combination with regular blood tests for staging and evaluating disease progression in MCRPC patients, but their sensitivity is known to be limited (Figure 2) [34,58].

For example, the multicenter retrospective study of Fendler et al. was designed to assess ${ }^{68}$ Ga-PSMA PET performance in CRPC patients without metastases on conventional imaging. Distant metastatic disease was found in 55\% of the included patients [64]. More sensitive detection with PSMA PET, and potentially earlier detection of metastatic disease, could impact the course of the disease and may facilitate the initiation of early treatment or timely therapy switch to another therapy [65]. However, the resulting improvement in oncological outcomes has not yet been demonstrated.

PSMA PET/CT could be performed for selecting patients for PSMA-directed RLT and (re)staging during or after treatment. It is essential to assess the level of PSMA expression before initiating RLT, as PSMA expression in MCRPC disease is known to be highly variable both within and between patients [66]. As a consequence, approximately one-third of the patients will not respond to PSMA-RLT. Hence, identifying predictors of treatment response could be of great value [67]. Ferdinandus et al. described that a higher platelet level and need for pain medication were significant predictors of a poor treatment response to ${ }^{177} \mathrm{Lu}-\mathrm{PSMA}-617$, and PSMA expression on ${ }^{68} \mathrm{Ga}-\mathrm{PSMA}$ PET/CT did not predict PSA response [68]. In a similar cohort, Emmett et al. aimed to identify predictors of treatment response in $\mathrm{mCRPC}$ patients treated with ${ }^{177} \mathrm{Lu}-\mathrm{PSMA}-617$. They found a strong correlation of PSMA expression (standardized uptake value (SUV): $S U V_{\text {max }}$ and $S U V_{\text {mean }}$ ) on ${ }^{68} \mathrm{Ga}-$ PSMA PET/CT at baseline imaging with a treatment response of more than $30 \%$. The location or volume of metastases were no predictors of treatment response [69]. 



Figure 2. A 79-year-old patient with CRPC after initial treatment with radiotherapy followed by hormonal therapy. Images illustrate improved detection of bone metastases using ${ }^{18} \mathrm{~F}$-DCFPyL PET/CT compared to bone scintigraphy (4 weeks interval). The PSA level at PET was $23 \mathrm{ng} / \mathrm{mL}$. On bone scintigraphy, faint uptake in the lumbar spine, the right acromioclavicular joint, the sternoclavicular, and hip joints were attributed to degenerative changes (A). Transversal ${ }^{18} \mathrm{~F}$-DCFPyL PET (B) and fused PET/CT (D) revealed two foci (red arrows) with intense PSMA-expression in the right iliac bone (SUV $\mathrm{Sax}_{\text {ax }}$ cranial lesion 6.2 and caudal lesion 17) and a sclerotic substrate on CT (C) and were classified as highly suspicious for bone metastases. Maximum intensity projection (E) demonstrated additional lymph node metastases above the diaphragm.

\subsection{Reporting PSMA PET/CT}

In recent years, a variety of reporting systems have been provided, including staging and lesion characterization, to improve consistent PSMA PET/CT describing [70,71]. Furthermore, the newly proposed E-PSMA consensus guidelines, endorsed by the European Association of Nuclear medicine, offers PSMA PET/CT interpretations and reporting statements to create more uniform and standardized reports for clinical use [72]. These guidelines incorporate earlier proposed PSMA-RADS (PSMA-reporting and Data system) and PROMISE (Prostate Cancer Molecular Imaging Standardized Evaluation) criteria. The PSMA-RADS categorizes PSMA PET/CT findings into five categories based on the probability of malignancy [71]. Furthermore, the PROMISE criteria include the intensity of PSMA expression (ranging from 0-3) and the molecular imaging TNM scores (miTNM score) [70]. Recently, a deep learning algorithm (aPROMISE) has been developed for the automated analysis of PSMA PET images to provide a consistent and standardized evaluation. However, the results of the aPROMISE technology require further validation before it can be translated into clinical practice [73].

\section{Theranostics}

\subsection{PSMA-Radioligand Therapy}

Aside from targeting PSMA for diagnostic purposes, another valuable feature of PSMA is its opportunity to serve as a target for delivering radionuclides (therapeutic agents) to cancer cells. Using the same target for diagnosis and therapeutics is referred to as 
Theranostics. Recently, novel radionuclides have been developed and proposed to be used as RLT in clinical practice for PCa management. For example, PSMA-ligands can be labeled with varying radionuclides, such as alpha and beta-emitters [10]. The most frequently used radionuclides for PSMA-RLT are Lutetium-177 $\left({ }^{177} \mathrm{Lu}\right)$, which decays by beta-emission, and Actinium-225 ( $\left.{ }^{225} \mathrm{Ac}\right)$, alpha-emission.

There are several clinically relevant differences between alpha and beta-particles (Table 1) [10]. Alpha-particles have a larger mass and carry higher energies. Alpha-particles have high linear-energy transfer (LET), defined as the amount of energy a particle can transmit along its track. This leads to more damage down their track and causes irreparable double-strand DNA breaks in tumor cells. Alpha-particles have a limited range in tissue (0.05-0.08 $\mathrm{mm})$, providing more controlled and selective irradiation of cancer cells with minimal impact on neighboring tissue $[10,74,75]$. In contrast, beta-particles have a small mass and a more extended range in tissue $(0.62 \mathrm{~mm})$. However, they have less energy in comparison with alpha particles. The LET produced by beta-particles is relatively low, resulting in single-strand DNA breaks, which are repairable and thus may be less effective in damaging PCa cells $[10,75]$. However, the advantage of the beta-emitter, ${ }^{177} \mathrm{Lu}-\mathrm{PSMA}$ is its favorable toxicity profile with less severe side-effects.

Table 1. Radionuclide properties of Actinium-225 and Lutetium-177. Reference: Sgouros G, Nature reviews (2020); 589-608 [10].

\begin{tabular}{ccc}
\hline Radionuclide Property & Actinium-225 & Lutetium-117 \\
\hline Therapeutic emission & $\alpha$ & $\beta-$ \\
Emission in range in tissue (mm) & $0.05-0.08$ & 0.62 \\
Radionuclide half-life (days) & 10.0 & 6.6 \\
\hline
\end{tabular}

\subsection{Beta-Emitter Radio-Ligand Therapy: Lutetium-PSMA}

PSMA-617 is the most commonly used ligand in RLT, which can be coupled to Lutetium-177, resulting in ${ }^{177} \mathrm{Lu}-\mathrm{PSMA}-617$ [76]. In addition, ${ }^{177} \mathrm{Lu}$ can also be attached to the PSMA Imaging and Therapy ligand ( ${ }^{177} \mathrm{Lu}$-PSMA I\&T) [77]. However, the use of ${ }^{177}$ Lu-PSMA-617 might be preferred in clinical practice compared to ${ }^{177}$ Lu-PSMA I\&T, possibly due to reduced uptake in the kidney [78]. RLT with ${ }^{177}$ Lu-PSMA has mainly been studied in $\mathrm{mCRPC}$, showing promising results as a potential treatment approach with a low toxicity profile $[11,12,67,79-83]$.

Several retrospective studies have outlined the biochemical (PSA) response of ${ }^{177} \mathrm{Lu}-$ PSMA-617 in mCRPC (see also Table S1) [84-90]. Kratochwil et al. reported any PSA response from baseline in 21 (70\%) of 30 patients, and a PSA decline of more than 50\% was found in $43 \%(13 / 30)$ after ${ }^{177}$ Lu-PSMA-617 treatment [88]. Similarly, in a study including $100 \mathrm{mCRPC}$ patients with a history of treatment with enzalutamide or abiraterone, Ahmadzadehfar et al. reported any PSA decline and a PSA decline of $>50 \%$ in $69 \%$ and $38 \%$ after ${ }^{177}$ Lu-PSMA-617 therapy [84]. In another study, Ahmadzadehfar et al. evaluated the patient response to the second and third cycle of ${ }^{177} \mathrm{Lu}-\mathrm{PSMA}-617$ in 52 patients and found PSA decline $>50 \%$ in $60 \%$ of the patients [85]. In a retrospective study of Brauer et al., any PSA decline was found in $91 \%$ of the patients $(n=45)$, and a PSA reduction of greater than 50\% occurred in 53\%. Any PSA decline after the first treatment cycle was significantly associated with a longer OS [86]. Rahbar et al. included patients with mCRPC treated with ${ }^{177} \mathrm{Lu}-\mathrm{PSMA}-617$ to assess the efficacy and safety of ${ }^{177}$ Lu-PSMA-617. A PSA decline of $50 \%$ or more was found in $45 \%$ of the patients. Grades 3 and 4 hematotoxicity occurred in $12 \%$ of the patients, and xerostomia was reported in $8 \%$ [89]. Another recent publication on ${ }^{177}$ Lu-PSMA-617 conducted by Rahbar et al. recorded any PSA response in $67 \%$ of the 104 included men and a PSA decline of $>50 \%$ in $33 \%$. Any PSA decline after the first cycle was associated with a longer OS than PSA progression (62.9 versus 47.0 weeks). A PSA decline greater than $50 \%$ was not prognostic for overall survival [90].

Hofman et al. conducted a single-center, phase II trial including mCRPC patients with progressive disease after conventional treatment. Treatment with ${ }^{177}$ Lu-PSMA-617 
treatment resulted in any PSA level decline in $97 \%$ of the patients and a PSA decline of $\geq 50 \%$ in $57 \%$. Most registered adverse events (AE) were xerostomia grade I ( $87 \%$ ), transient nausea (50\%), and fatigue grade I-II (50\%). Grade 3-4 thrombocytopenia due to ${ }^{177}$ Lu-PSMA-617 occurred in $13 \%$ of the patients [80].

The randomized, multicenter, phase II TheraP trial compared ${ }^{177}$ Lu-PSMA-617 (up to six cycles every six weeks) to cabazitaxel (up to 10 cycles every three weeks) in 200 patients with progressive post-docetaxel mCRPC. Patients treated with ${ }^{177}$ Lu-PSMA-617 showed a $\geq 50 \%$ PSA response more frequently than patients treated with cabazitaxel (66\% versus $37 \%, p<0.0001)$. In addition, fewer grade III and IV AE were observed in patients who underwent ${ }^{177}$ Lu-PSMA-617 treatment (33\% versus 53\%) [11].

Furthermore, the randomized, phase III VISION trial by Sartor et al. assessed 831 patients with mCRPC diagnosed with at least one positive lesion on ${ }^{68} \mathrm{Ga}-\mathrm{PSMA}-11$ PET/CT. The patients previously underwent treatment with minimal one androgen receptor signaling pathway inhibitor and taxane chemotherapy. The patients were randomized 2:1 to receive ${ }^{177}$ Lu-PSMA-617 (every six weeks up to four-six cycles) plus standard of care (SOC; $(n=551)$ or SOC alone $(n=280)$. The median imaging-based progression-free survival was improved by 5.3 months in the ${ }^{177} \mathrm{Lu}-\mathrm{PSMA}-617$ group compared to the control group (8.7 versus 3.4 months, respectively; $p<0.001$ ). In addition, there was a significant median OS benefit in favor of ${ }^{177} \mathrm{Lu}$-PSMA-617 (15.3 versus 11.3 months, respectively; $p<0.001$ ). As expected, treatment with ${ }^{177} \mathrm{Lu}-\mathrm{PSMA}-617$ led to a higher incidence of grade $3 \mathrm{AE}$, or higher, than the control group (52\% versus 38\%). The most-reported AE were fatigue, dry mouth, and nausea grade I or II. Nevertheless, a low incidence of AE led to alternation of the doses or discontinuation of the study, and treatment with ${ }^{177} \mathrm{Lu}-\mathrm{PSMA}-617$ was considered safe [12]. Challenges remain in the prediction of treatment response and survival in ${ }^{177}$ Lu-PSMA therapy. In several studies, (changes in) metrics quantifying the burden of PSMA-positive disease on PET were associated with treatment response and survival to ${ }^{177} \mathrm{Lu}-\mathrm{PSMA}$ radioligand therapy in patients with $\mathrm{MCRPC}$ [91-93]

There is increasing interest in positioning PSMA-radioligand therapy in the (earlier) hormone-sensitive stage. It is hypothesized that in metastatic hormone-sensitive prostate cancer (mHSPCa), the initiation of androgen deprivation therapy (ADT) can be deferred, and, ultimately, the OS could be improved. Several studies are ongoing in patients with mHSPCa, and results are eagerly awaited [NCT04443062; NCT04343885; NCT04720157].

\subsection{Alpha-Emitter Radioligand Therapy: Actinium-PSMA}

The most commonly used alpha-emitter for PSMA-ligand treatment is ${ }^{225}$ Ac-PSMA617 (see also Table S2). A retrospective study by Kratochwil et al. included 40 patients with mCRPC who underwent treatment with ${ }^{225}$ Ac-PSMA-617 (every two months up to three cycles). In total, $63 \%$ of patients had a PSA decline of more than $50 \%$, and $87 \%$ had any PSA response. Remarkably, five patients (13\%) showed a response for over two years. Unfortunately, four patients (10\%) dropped out of this study because of (severe) side effects (xerostomia), and five patients (13\%) terminated treatment due to lack of response following the first cycle [94]. Sathekge et al. enrolled 73 patients with mCRPC for treatment with ${ }^{225}$ Ac-PSMA-617 (every eight weeks, most patients received up to two-five cycles). A total of $82 \%$ of patients had any PSA response in this cohort, and $70 \%$ had a PSA decline of $>50 \%$. Grades I and II xerostomia were reported in $85 \%$ of the patients, not leading to treatment discontinuation [95].

${ }^{225}$ Ac-PSMA-617 could benefit patients who did not respond to prior ${ }^{177}$ Lu-PSMA-RLT. Several studies included patients previously treated with ${ }^{177} \mathrm{Lu}-\mathrm{PSMA}-\mathrm{RLT}$. Yadav et al. prospectively enrolled 28 men with $\mathrm{mCRPC}$ to receive ${ }^{225}$ Ac-PSMA-617 treatment (median of three cycles). A total of $54 \%$ of these had prior exposure to ${ }^{177} \mathrm{Lu}$-PSMA therapy. After the first treatment cycle, $25 \%$ of the patients had a PSA decline of $\geq 50 \%$, which increased to $39 \%$ at the end of follow-up. Any PSA decline was found in 78.6\%. Patients' refractory to ${ }^{177}$ Lu-PSMA less frequently showed a PSA decline of $\geq 50 \%$ than patients with no history of ${ }^{177}$ Lu-PSMA therapy (26.6\% versus $53.8 \%$ ). Half of the patients reported fatigue and 
$29 \%$ xerostomia (grade I/II) as AE [96]. In the study by Fuerecker et al., ${ }^{225}$ Ac-PSMA-617 was offered every eight weeks (median of two cycles) to 26 patients with mCRPC who progressed after a median of four cycles of ${ }^{177} \mathrm{Lu}$-PSMA treatment. In $88 \%$ of the patients, any PSA decline was described, and $65 \%$ had a PSA decline of $\geq 50 \%$. Grade I/II xerostomia was observed in all patients, leading to study discontinuation in six patients (23\%). The reported hematological AE (grade III/IV) were thrombocytopenia (19\%), leucopenia (27\%), and anemia (35\%) [97]. Although these retrospective studies seem promising, further prospective data is warranted. Unfortunately, the clinical application of ${ }^{225}$ Ac-PSMA RLT is sparse due to the limited availability of ${ }^{225} \mathrm{Ac}$ [98].

\section{Conclusions}

In recent years, PSMA PET has gained an increasingly important role in both initial diagnosis and at the biochemical recurrence of disease in patients with prostate cancer. In addition, PSMA PET/CT is being used more frequently during follow-up of the disease to assess treatment response. Aside from targeting the PSMA protein for diagnostic purposes, PSMA may also be a target for combined diagnostics and therapeutic purposes, the Theranostics approach. PSMA radioligand therapy has shown to be an effective and safe therapeutic option for patients with metastatic castration-resistant prostate cancer. Its oncological effect is currently being investigated in patients presenting with metastatic hormone-sensitive prostate cancer.

Supplementary Materials: The following supporting information can be downloaded at: https: / / www.mdpi.com/article/10.3390/cancers14051169/s1, Table S1: Summary of 177Lu-PSMA-617 studies; Table S2. Summary of ${ }^{225}$ Ac-PSMA-617 studies.

Author Contributions: Conceptualization, W.I.L., M.C.F.C., D.E.O.-L., and A.N.V.; Writing-original draft, W.I.L.; Writing—review and editing, M.C.F.C., D.M., D.E.O.-L., A.N.V., R.B., and N.H.H. All authors have read and agreed to the published version of the manuscript.

Funding: This research was partially financed by Cancer Center Amsterdam, Amsterdam, the Netherlands.

Institutional Review Board Statement: Ethical review and approval were waived for this narrative review, due to its nature.

Informed Consent Statement: The patients whom scans are presented in Figures 1 and 2 gave their written informed consent for data to be used for scientifical purposes.

Data Availability Statement: No new data were created or analyzed in this study. Data sharing is not applicable to this article.

Conflicts of Interest: The authors declare no conflict of interest.

\section{References}

1. Sung, H.; Ferlay, J.; Siegel, R.L.; Laversanne, M.; Soerjomataram, I.; Jemal, A.; Bray, F. Global Cancer Statistics 2020: GLOBOCAN Estimates of Incidence and Mortality Worldwide for 36 Cancers in 185 Countries. CA Cancer J. Clin. 2021, 71, 209-249. [CrossRef] [PubMed]

2. Haffner, M.C.; Zwart, W.; Roudier, M.P.; True, L.D.; Nelson, W.G.; Epstein, J.I.; De Marzo, A.M.; Nelson, P.S.; Yegnasubramanian, S. Genomic and phenotypic heterogeneity in prostate cancer. Nat. Rev. Urol. 2021, 18, 79-92. [CrossRef] [PubMed]

3. Mottet, N.; van den Bergh, R.C.N.; Briers, E.; Van den Broeck, T.; Cumberbatch, M.G.; De Santis, M.; Fanti, S.; Fossati, N.; Gandaglia, G.; Gillessen, S.; et al. EAU-EANM-ESTRO-ESUR-SIOG Guidelines on Prostate Cancer-2020 Update. Part 1: Screening, Diagnosis, and Local Treatment with Curative Intent. Eur. Urol. 2020, 79, 243-262. [CrossRef] [PubMed]

4. Chen, Y.; Pullambhatla, M.; Foss, C.A.; Byun, Y.; Nimmagadda, S.; Senthamizhchelvan, S.; Sgouros, G.; Mease, R.C.; Pomper, M.G. 2-(3-\{1-Carboxy-5-[(6-[18F]fluoro-pyridine-3-carbonyl)-amino]-pentyl\}-ureido)-pen tanedioic acid, [18F]DCFPyL, a PSMA-based PET imaging agent for prostate cancer. Clin. Cancer Res. 2011, 17, 7645-7653. [CrossRef]

5. Silver, D.A.; Pellicer, I.; Fair, W.R.; Heston, W.D.; Cordon-Cardo, C. Prostate-specific membrane antigen expression in normal and malignant human tissues. Clin. Cancer Res. 1997, 3, 81-85.

6. de Galiza Barbosa, F.; Queiroz, M.A.; Nunes, R.F.; Costa, L.B.; Zaniboni, E.C.; Marin, J.F.G.; Cerri, G.G.; Buchpiguel, C.A. Nonprostatic diseases on PSMA PET imaging: A spectrum of benign and malignant findings. Cancer Imaging 2020, $20,23$. [CrossRef] 
7. Morris, M.J.; Rowe, S.P.; Gorin, M.A.; Saperstein, L.; Pouliot, F.; Josephson, D.; Wong, J.Y.C.; Pantel, A.R.; Cho, S.Y.; Gage, K.L.; et al. Diagnostic Performance of (18)F-DCFPyL-PET/CT in Men with Biochemically Recurrent Prostate Cancer: Results from the CONDOR Phase III, Multicenter Study. Clin. Cancer Res. 2021, 27, 3674-3682. [CrossRef]

8. Pienta, K.J.; Gorin, M.A.; Rowe, S.P.; Carroll, P.R.; Pouliot, F.; Probst, S.; Saperstein, L.; Preston, M.A.; Alva, A.S.; Patnaik, A.; et al. A Phase 2/3 Prospective Multicenter Study of the Diagnostic Accuracy of Prostate Specific Membrane Antigen PET/CT with (18)F-DCFPyL in Prostate Cancer Patients (OSPREY). J. Urol. 2021, 206, 52-61. [CrossRef]

9. Ceci, F.; Oprea-Lager, D.E.; Emmett, L.; Adam, J.A.; Bomanji, J.; Czernin, J.; Eiber, M.; Haberkorn, U.; Hofman, M.S.; Hope, T.A.; et al. E-PSMA: The EANM standardized reporting guidelines v1.0 for PSMA-PET. Eur. J. Nucl. Med. Mol. Imaging 2021, 48, 1626-1638. [CrossRef]

10. Sgouros, G.; Bodei, L.; McDevitt, M.R.; Nedrow, J.R. Radiopharmaceutical therapy in cancer: Clinical advances and challenges. Nat. Rev. Drug. Discov. 2020, 19, 589-608. [CrossRef]

11. Hofman, M.S.; Emmett, L.; Sandhu, S.; Iravani, A.; Joshua, A.M.; Goh, J.C.; Pattison, D.A.; Tan, T.H.; Kirkwood, I.D.; Ng, S.; et al. [(177)Lu]Lu-PSMA-617 versus cabazitaxel in patients with metastatic castration-resistant prostate cancer (TheraP): A randomised, open-label, phase 2 trial. Lancet 2021, 397, 797-804. [CrossRef]

12. Sartor, O.; de Bono, J.; Chi, K.N.; Fizazi, K.; Herrmann, K.; Rahbar, K.; Tagawa, S.T.; Nordquist, L.T.; Vaishampayan, N.; El-Haddad, G.; et al. Lutetium-177-PSMA-617 for Metastatic Castration-Resistant Prostate Cancer. N. Engl. J. Med. 2021, 385, $1091-1103$. [CrossRef] [PubMed]

13. Epstein, J.I.; Egevad, L.; Amin, M.B.; Delahunt, B.; Srigley, J.R.; Humphrey, P.A.; Grading, C. The 2014 International Society of Urological Pathology (ISUP) Consensus Conference on Gleason Grading of Prostatic Carcinoma: Definition of Grading Patterns and Proposal for a New Grading System. Am. J. Surg. Pathol. 2016, 40, 244-252. [CrossRef] [PubMed]

14. Danneman, D.; Drevin, L.; Delahunt, B.; Samaratunga, H.; Robinson, D.; Bratt, O.; Loeb, S.; Stattin, P.; Egevad, L. Accuracy of prostate biopsies for predicting Gleason score in radical prostatectomy specimens: Nationwide trends 2000-2012. BJU Int. 2017, 119, 50-56. [CrossRef] [PubMed]

15. Calais, J.; Ceci, F.; Eiber, M.; Hope, T.A.; Hofman, M.S.; Rischpler, C.; Bach-Gansmo, T.; Nanni, C.; Savir-Baruch, B.; Elashoff, D.; et al. (18)F-fluciclovine PET-CT and (68)Ga-PSMA-11 PET-CT in patients with early biochemical recurrence after prostatectomy: A prospective, single-centre, single-arm, comparative imaging trial. Lancet Oncol. 2019, 20, 1286-1294. [CrossRef]

16. Hofman, M.S.; Lawrentschuk, N.; Francis, R.J.; Tang, C.; Vela, I.; Thomas, P.; Rutherford, N.; Martin, J.M.; Frydenberg, M.; Shakher R.; et al. Prostate-specific membrane antigen PET-CT in patients with high-risk prostate cancer before curative-intent surgery or radiotherapy (proPSMA): A prospective, randomised, multicentre study. Lancet 2020, 395, 1208-1216. [CrossRef]

17. Brierley, J.D.; Gospodarowicz, M.K.; Wittekind, C. TNM Classification of Malignant Tumors, 8th ed.; UICC International Union Against Cancer: Geneva, Switzerland, 2017.

18. James, N.D.; Spears, M.R.; Clarke, N.W.; Dearnaley, D.P.; De Bono, J.S.; Gale, J.; Hetherington, J.; Hoskin, P.J.; Jones, R.J.; Laing, R.; et al. Survival with Newly Diagnosed Metastatic Prostate Cancer in the "Docetaxel Era": Data from 917 Patients in the Control Arm of the STAMPEDE Trial (MRC PR08, CRUK/06/019). Eur. Urol. 2015, 67, 1028-1038. [CrossRef] [PubMed]

19. Hövels, A.M.; Heesakkers, R.A.; Adang, E.M.; Jager, G.J.; Strum, S.; Hoogeveen, Y.L.; Severens, J.L.; Barentsz, J.O. The diagnostic accuracy of CT and MRI in the staging of pelvic lymph nodes in patients with prostate cancer: A meta-analysis. Clin. Radiol. 2008, 63, 387-395. [CrossRef] [PubMed]

20. Shen, G.; Deng, H.; Hu, S.; Jia, Z. Comparison of choline-PET/CT, MRI, SPECT, and bone scintigraphy in the diagnosis of bone metastases in patients with prostate cancer: A meta-analysis. Skelet. Radiol. 2014, 43, 1503-1513. [CrossRef]

21. Sanchez-Crespo, A. Comparison of Gallium-68 and Fluorine-18 imaging characteristics in positron emission tomography. Appl. Radiat. Isot. 2013, 76, 55-62. [CrossRef]

22. Fendler, W.P.; Eiber, M.; Beheshti, M.; Bomanji, J.; Ceci, F.; Cho, S.; Giesel, F.; Haberkorn, U.; Hope, T.A.; Kopka, K.; et al. (68)Ga-PSMA PET/CT: Joint EANM and SNMMI procedure guideline for prostate cancer imaging: Version 1.0. Eur. J. Nucl. Med. Mol. Imaging 2017, 44, 1014-1024. [CrossRef] [PubMed]

23. Giesel, F.L.; Knorr, K.; Spohn, F.; Will, L.; Maurer, T.; Flechsig, P.; Neels, O.; Schiller, K.; Amaral, H.; Weber, W.A. Detection efficacy of 18F-PSMA-1007 PET/CT in 251 patients with biochemical recurrence of prostate cancer after radical prostatectomy. J. Nucl. Med. 2019, 60, 362-368. [CrossRef]

24. Rahbar, K.; Afshar-Oromieh, A.; Seifert, R.; Wagner, S.; Schäfers, M.; Bögemann, M.; Weckesser, M. Diagnostic performance of 18 F-PSMA-1007 PET/CT in patients with biochemical recurrent prostate cancer. Eur. J. Nucl. Med. Mol. Imaging 2018, 45, 2055-2061.

25. Rauscher, I.; Krönke, M.; König, M.; Gafita, A.; Maurer, T.; Horn, T.; Schiller, K.; Weber, W.; Eiber, M. Matched-Pair Comparison of (68)Ga-PSMA-11 PET/CT and (18)F-PSMA-1007 PET/CT: Frequency of Pitfalls and Detection Efficacy in Biochemical Recurrence After Radical Prostatectomy. J. Nucl. Med. 2020, 61, 51-57. [CrossRef] [PubMed]

26. Wondergem, M.; van der Zant, F.M.; Broos, W.A.M.; Knol, R.J.J. Matched-Pair Comparison of (18)F-DCFPyL PET/CT and (18)F-PSMA-1007 PET/CT in 240 Prostate Cancer Patients: Interreader Agreement and Lesion Detection Rate of Suspected Lesions. J. Nucl. Med. 2021, 62, 1422-1429. [CrossRef]

27. Giesel, F.L.; Hadaschik, B.; Cardinale, J.; Radtke, J.; Vinsensia, M.; Lehnert, W.; Kesch, C.; Tolstov, Y.; Singer, S.; Grabe, N.; et al F-18 labelled PSMA-1007: Biodistribution, radiation dosimetry and histopathological validation of tumor lesions in prostate cancer patients. Eur. J. Nucl. Med. Mol. Imaging 2017, 44, 678-688. [CrossRef] 
28. Perera, M.; Papa, N.; Roberts, M.; Williams, M.; Udovicich, C.; Vela, I.; Christidis, D.; Bolton, D.; Hofman, M.S.; Lawrentschuk, N.; et al. Gallium-68 Prostate-specific Membrane Antigen Positron Emission Tomography in Advanced Prostate Cancer-Updated Diagnostic Utility, Sensitivity, Specificity, and Distribution of Prostate-specific Membrane Antigen-avid Lesions: A Systematic Review and Meta-analysis. Eur. Urol. 2020, 77, 403-417. [CrossRef]

29. Jansen, B.H.E.; Bodar, Y.J.L.; Zwezerijnen, G.J.C.; Meijer, D.; van der Voorn, J.P.; Nieuwenhuijzen, J.A.; Wondergem, M.; Roeleveld, T.A.; Boellaard, R.; Hoekstra, O.S.; et al. Pelvic lymph-node staging with (18)F-DCFPyL PET/CT prior to extended pelvic lymph-node dissection in primary prostate cancer-the SALT trial. Eur. J. Nucl. Med. Mol. Imaging 2021, 48, 509-520. [CrossRef] [PubMed]

30. van Kalmthout, L.W.M.; van Melick, H.H.E.; Lavalaye, J.; Meijer, R.P.; Kooistra, A.; de Klerk, J.M.H.; Braat, A.; Kaldeway, H.P.; de Bruin, P.C.; de Keizer, B.; et al. Prospective Validation of Gallium-68 Prostate Specific Membrane Antigen-Positron Emission Tomography/Computerized Tomography for Primary Staging of Prostate Cancer. J. Urol. 2020, 203, 537-545. [CrossRef] [PubMed]

31. Meijer, D.; de Barros, H.A.; van Leeuwen, P.J.; Bodar, Y.J.L.; van der Poel, H.G.; Donswijk, M.L.; Hendrikse, N.H.; van Moorselaar, R.J.A.; Nieuwenhuijzen, J.A.; Oprea-Lager, D.E.; et al. The Predictive Value of Preoperative Negative Prostate Specific Membrane Antigen Positron Emission Tomography Imaging for Lymph Node Metastatic Prostate Cancer. J. Urol. 2021, 205, $1655-1662$. [CrossRef]

32. Ploussard, G.; Staerman, F.; Pierrevelcin, J.; Saad, R.; Beauval, J.B.; Roupret, M.; Audenet, F.; Peyromaure, M.; Delongchamps, N.B.; Vincendeau, S.; et al. Predictive factors of oncologic outcomes in patients who do not achieve undetectable prostate specific antigen after radical prostatectomy. J. Urol. 2013, 190, 1750-1756. [CrossRef] [PubMed]

33. Wiegel, T.; Bartkowiak, D.; Bottke, D.; Thamm, R.; Hinke, A.; Stöckle, M.; Rübe, C.; Semjonow, A.; Wirth, M.; Störkel, S.; et al. Prostate-specific antigen persistence after radical prostatectomy as a predictive factor of clinical relapse-free survival and overall survival: 10-year data of the ARO 96-02 trial. Int. J. Radiat. Oncol. Biol. Phys. 2015, 91, 288-294. [CrossRef] [PubMed]

34. Cornford, P.; van den Bergh, R.C.N.; Briers, E.; Van den Broeck, T.; Cumberbatch, M.G.; De Santis, M.; Fanti, S.; Fossati, N.; Gandaglia, G.; Gillessen, S.; et al. EAU-EANM-ESTRO-ESUR-SIOG Guidelines on Prostate Cancer. Part II-2020 Update: Treatment of Relapsing and Metastatic Prostate Cancer. Eur. Urol. 2021, 79, 263-282. [CrossRef] [PubMed]

35. Preisser, F.; Chun, F.K.H.; Pompe, R.S.; Heinze, A.; Salomon, G.; Graefen, M.; Huland, H.; Tilki, D. Persistent Prostate-Specific Antigen After Radical Prostatectomy and Its Impact on Oncologic Outcomes. Eur. Urol. 2019, 76, 106-114. [CrossRef] [PubMed]

36. Sood, A.; Keeley, J.; Palma-Zamora, I.; Arora, S.; Dalela, D.; Olson, P.; Hanna, R.; Cotter, D.; Jeong, W.; Elshaikh, M.; et al Ten-year disease progression and mortality rates in men who experience biochemical recurrence versus persistence after radical prostatectomy and undergo salvage radiation therapy: A post-hoc analysis of RTOG 9601 trial data. Urol. Oncol. Semin. Orig. Investig. 2020, 38, 599.e591-599.e598. [CrossRef]

37. Schmidt-Hegemann, N.S.; Fendler, W.P.; Ilhan, H.; Herlemann, A.; Buchner, A.; Stief, C.; Eze, C.; Rogowski, P.; Li, M.; Bartenstein, P.; et al. Outcome after PSMA PET/CT based radiotherapy in patients with biochemical persistence or recurrence after radical prostatectomy. Radiat. Oncol. 2018, 13, 37. [CrossRef]

38. Farolfi, A.; Gafita, A.; Calais, J.; Eiber, M.; Afshar-Oromieh, A.; Spohn, F.; Barbato, F.; Weber, M.; Ilhan, H.; Cervati, V.; et al. ${ }^{68}$ GaPSMA-11 Positron Emission Tomography Detects Residual Prostate Cancer after Prostatectomy in a Multicenter Retrospective Study. J. Urol. 2019, 202, 1174-1181. [CrossRef]

39. Meijer, D.; Donswijk, M.L.; Bodar, Y.J.L.; van Leeuwen, P.J.; Poel, H.G.V.; Vogel, W.V.; Nieuwenhuijzen, J.A.; Hendrikse, N.H.; Oprea-Lager, D.E.; Vis, A.N. Biochemical Persistence of Prostate-Specific Antigen After Robot-Assisted Laparoscopic Radical Prostatectomy: Tumor Localizations Using PSMA PET/CT Imaging. J. Nucl. Med. 2021, 62, 961-967. [CrossRef]

40. Cookson, M.S.; Aus, G.; Burnett, A.L.; Canby-Hagino, E.D.; D’Amico, A.V.; Dmochowski, R.R.; Eton, D.T.; Forman, J.D.; Goldenberg, S.L.; Hernandez, J.; et al. Variation in the definition of biochemical recurrence in patients treated for localized prostate cancer: The American Urological Association Prostate Guidelines for Localized Prostate Cancer Update Panel report and recommendations for a standard in the reporting of surgical outcomes. J. Urol. 2007, 177, 540-545. [CrossRef]

41. Roach, M., 3rd; Hanks, G.; Thames, H., Jr.; Schellhammer, P.; Shipley, W.U.; Sokol, G.H.; Sandler, H. Defining biochemical failure following radiotherapy with or without hormonal therapy in men with clinically localized prostate cancer: Recommendations of the RTOG-ASTRO Phoenix Consensus Conference. Int. J. Radiat. Oncol. Biol. Phys. 2006, 65, 965-974. [CrossRef]

42. Wondergem, M.; Jansen, B.H.E.; van der Zant, F.M.; van der Sluis, T.M.; Knol, R.J.J.; van Kalmthout, L.W.M.; Hoekstra, O.S.; van Moorselaar, R.J.A.; Oprea-Lager, D.E.; Vis, A.N. Early lesion detection with 18F-DCFPyL PET/CT in 248 patients with biochemically recurrent prostate cancer. Eur. J. Nucl. Med. Mol. Imaging 2019, 46, 1911-1918. [CrossRef] [PubMed]

43. Jansen, B.H.E.; van Leeuwen, P.J.; Wondergem, M.; van der Sluis, T.M.; Nieuwenhuijzen, J.A.; Knol, R.J.J.; van Moorselaar, R.J.A.; van der Poel, H.G.; Oprea-Lager, D.E.; Vis, A.N. Detection of Recurrent Prostate Cancer Using Prostate-specific Membrane Antigen Positron Emission Tomography in Patients not Meeting the Phoenix Criteria for Biochemical Recurrence After Curative Radiotherapy. Eur. Urol. Oncol 2021, 4, 821-825. [CrossRef] [PubMed]

44. Afshar-Oromieh, A.; Zechmann, C.M.; Malcher, A.; Eder, M.; Eisenhut, M.; Linhart, H.G.; Holland-Letz, T.; Hadaschik, B.A.; Giesel, F.L.; Debus, J.; et al. Comparison of PET imaging with a (68)Ga-labelled PSMA ligand and (18)F-choline-based PET/CT for the diagnosis of recurrent prostate cancer. Eur. J. Nucl. Med. Mol. Imaging 2014, 41, 11-20. [CrossRef] [PubMed] 
45. Bluemel, C.; Krebs, M.; Polat, B.; Linke, F.; Eiber, M.; Samnick, S.; Lapa, C.; Lassmann, M.; Riedmiller, H.; Czernin, J.; et al. 68Ga-PSMA-PET/CT in Patients With Biochemical Prostate Cancer Recurrence and Negative 18F-Choline-PET/CT. Clin. Nucl. Med. 2016, 41, 515-521. [CrossRef]

46. Morigi, J.J.; Stricker, P.D.; van Leeuwen, P.J.; Tang, R.; Ho, B.; Nguyen, Q.; Hruby, G.; Fogarty, G.; Jagavkar, R.; Kneebone, A.; et al. Prospective Comparison of ${ }^{18}$ F-Fluoromethylcholine Versus ${ }^{68}$ Ga-PSMA PET/CT in Prostate Cancer Patients Who Have Rising PSA After Curative Treatment and Are Being Considered for Targeted Therapy. J. Nucl. Med. 2015, 56, 1185-1190. [CrossRef]

47. Schwenck, J.; Rempp, H.; Reischl, G.; Kruck, S.; Stenzl, A.; Nikolaou, K.; Pfannenberg, C.; la Fougere, C. Comparison of (68)Ga-labelled PSMA-11 and (11)C-choline in the detection of prostate cancer metastases by PET/CT. Eur. J. Nucl. Med. Mol. Imaging 2017, 44, 92-101. [CrossRef]

48. Evans, J.D.; Jethwa, K.R.; Ost, P.; Williams, S.; Kwon, E.D.; Lowe, V.J.; Davis, B.J. Prostate cancer-specific PET radiotracers: A review on the clinical utility in recurrent disease. Pract. Radiat. Oncol. 2018, 8, 28-39. [CrossRef]

49. Calais, J.; Fendler, W.P.; Eiber, M.; Gartmann, J.; Chu, F.-I.; Nickols, N.G.; Reiter, R.E.; Rettig, M.B.; Marks, L.S.; Ahlering, T.E.; et al. Impact of ${ }^{68}$ Ga-PSMA-11 PET/CT on the Management of Prostate Cancer Patients with Biochemical Recurrence. J. Nucl. Med. 2018, 59, 434-441. [CrossRef]

50. Meijer, D.; van Leeuwen, P.J.; Oosterholt, P.M.J.; Bodar, Y.J.L.; van der Poel, H.G.; Hendrikse, N.H.; Donswijk, M.L.; Wondergem, M.; Vellekoop, A.E.; van Moorselaar, R.J.A.; et al. Management impact of 18F-DCFPyL PET/CT in hormone-sensitive prostate cancer patients with biochemical recurrence after definitive treatment: A multicenter retrospective study. Eur. J. Nucl. Med. Mol. Imaging 2021, 48, 2960-2969. [CrossRef] [PubMed]

51. Song, H.; Harrison, C.; Duan, H.; Guja, K.; Hatami, N.; Franc, B.L.; Moradi, F.; Aparici, C.M.; Davidzon, G.A.; Iagaru, A. Prospective Evaluation of ${ }^{18} \mathrm{~F}$-DCFPyL PET/CT in Biochemically Recurrent Prostate Cancer in an Academic Center: A Focus on Disease Localization and Changes in Management. J. Nucl. Med. 2020, 61, 546-551. [CrossRef]

52. Calais, J.; Czernin, J.; Cao, M.; Kishan, A.U.; Hegde, J.V.; Shaverdian, N.; Sandler, K.; Chu, F.I.; King, C.R.; Steinberg, M.L.; et al. (68)Ga-PSMA-11 PET/CT Mapping of Prostate Cancer Biochemical Recurrence After Radical Prostatectomy in 270 Patients with a PSA Level of Less Than $1.0 \mathrm{ng} / \mathrm{mL}$ : Impact on Salvage Radiotherapy Planning. J. Nucl. Med. 2018, 59, 230-237. [CrossRef] [PubMed]

53. Mena, E.; Lindenberg, L.; Choyke, P. The Impact of PSMA PET/CT Imaging in Prostate Cancer Radiation Treatment. Semin. Nucl. Med. 2022. [CrossRef]

54. Roach, P.J.; Francis, R.; Emmett, L.; Hsiao, E.; Kneebone, A.; Hruby, G.; Eade, T.; Nguyen, Q.A.; Thompson, B.D.; Cusick, T.; et al. The Impact of (68)Ga-PSMA PET/CT on Management Intent in Prostate Cancer: Results of an Australian Prospective Multicenter Study. J. Nucl. Med. 2018, 59, 82-88. [CrossRef] [PubMed]

55. Kneebone, A.; Hruby, G.; Ainsworth, H.; Byrne, K.; Brown, C.; Guo, L.; Guminski, A.; Eade, T. Stereotactic Body Radiotherapy for Oligometastatic Prostate Cancer Detected via Prostate-specific Membrane Antigen Positron Emission Tomography. Eur. Urol. Oncol. 2018, 1, 531-537. [CrossRef] [PubMed]

56. Ost, P.; Reynders, D.; Decaestecker, K.; Fonteyne, V.; Lumen, N.; Bruycker, A.D.; Lambert, B.; Delrue, L.; Bultijnck, R.; Goetghebeur, E.; et al. Surveillance or metastasis-directed therapy for oligometastatic prostate cancer recurrence (STOMP): Five-year results of a randomized phase II trial. J. Clin. Oncol. 2020, 38, 10. [CrossRef]

57. Phillips, R.; Shi, W.Y.; Deek, M.; Radwan, N.; Lim, S.J.; Antonarakis, E.S.; Rowe, S.P.; Ross, A.E.; Gorin, M.A.; Deville, C.; et al. Outcomes of Observation vs Stereotactic Ablative Radiation for Oligometastatic Prostate Cancer: The ORIOLE Phase 2 Randomized Clinical Trial. JAMA Oncol. 2020, 6, 650-659. [CrossRef] [PubMed]

58. Scher, H.I.; Morris, M.J.; Stadler, W.M.; Higano, C.; Basch, E.; Fizazi, K.; Antonarakis, E.S.; Beer, T.M.; Carducci, M.A.; Chi, K.N.; et al. Trial Design and Objectives for Castration-Resistant Prostate Cancer: Updated Recommendations From the Prostate Cancer Clinical Trials Working Group 3. J. Clin. Oncol. Off. J. Am. Soc. Clin. Oncol. 2016, 34, 1402-1418. [CrossRef] [PubMed]

59. Hussain, M.; Fizazi, K.; Saad, F.; Rathenborg, P.; Shore, N.; Ferreira, U.; Ivashchenko, P.; Demirhan, E.; Modelska, K.; Phung, D.; et al. Enzalutamide in Men with Nonmetastatic, Castration-Resistant Prostate Cancer. N. Engl. J. Med. 2018, 378, $2465-2474$. [CrossRef]

60. Ryan, C.J.; Smith, M.R.; Fizazi, K.; Saad, F.; Mulders, P.F.; Sternberg, C.N.; Miller, K.; Logothetis, C.J.; Shore, N.D.; Small, E.J.; et al. Abiraterone acetate plus prednisone versus placebo plus prednisone in chemotherapy-naive men with metastatic castrationresistant prostate cancer (COU-AA-302): Final overall survival analysis of a randomised, double-blind, placebo-controlled phase 3 study. Lancet Oncol. 2015, 16, 152-160. [CrossRef]

61. Scher, H.I.; Fizazi, K.; Saad, F.; Taplin, M.E.; Sternberg, C.N.; Miller, K.; de Wit, R.; Mulders, P.; Chi, K.N.; Shore, N.D.; et al. Increased survival with enzalutamide in prostate cancer after chemotherapy. N. Engl. J. Med. 2012, 367, 1187-1197. [CrossRef]

62. Smith, M.R.; Saad, F.; Chowdhury, S.; Oudard, S.; Hadaschik, B.A.; Graff, J.N.; Olmos, D.; Mainwaring, P.N.; Lee, J.Y.; Uemura, H.; et al. Apalutamide Treatment and Metastasis-free Survival in Prostate Cancer. N. Engl. J. Med. 2018, 378, 1408-1418. [CrossRef]

63. Tannock, I.F.; de Wit, R.; Berry, W.R.; Horti, J.; Pluzanska, A.; Chi, K.N.; Oudard, S.; Theodore, C.; James, N.D.; Turesson, I.; et al. Docetaxel plus prednisone or mitoxantrone plus prednisone for advanced prostate cancer. N. Engl. J. Med. 2004, 351, 1502-1512. [CrossRef] [PubMed]

64. Fendler, W.P.; Weber, M.; Iravani, A.; Hofman, M.S.; Calais, J.; Czernin, J.; Ilhan, H.; Saad, F.; Small, E.J.; Smith, M.R.; et al. Prostate-Specific Membrane Antigen Ligand Positron Emission Tomography in Men with Nonmetastatic Castration-Resistant Prostate Cancer. Clin. Cancer Res. 2019, 25, 7448-7454. [CrossRef] [PubMed] 
65. Farolfi, A.; Calderoni, L.; Mattana, F.; Mei, R.; Telo, S.; Fanti, S.; Castellucci, P. Current and Emerging Clinical Applications of PSMA PET Diagnostic Imaging for Prostate Cancer. J. Nucl. Med. 2021, 62, 596-604. [CrossRef]

66. Paschalis, A.; Sheehan, B.; Riisnaes, R.; Rodrigues, D.N.; Gurel, B.; Bertan, C.; Ferreira, A.; Lambros, M.B.K.; Seed, G.; Yuan, W.; et al. Prostate-specific Membrane Antigen Heterogeneity and DNA Repair Defects in Prostate Cancer. Eur. Urol. 2019, 76, 469-478. [CrossRef] [PubMed]

67. Kim, Y.J.; Kim, Y.I. Therapeutic Responses and Survival Effects of 177Lu-PSMA-617 Radioligand Therapy in Metastatic CastrateResistant Prostate Cancer: A Meta-analysis. Clin. Nucl. Med. 2018, 43, 728-734. [CrossRef]

68. Ferdinandus, J.; Eppard, E.; Gaertner, F.C.; Kurpig, S.; Fimmers, R.; Yordanova, A.; Hauser, S.; Feldmann, G.; Essler, M.; Ahmadzadehfar, H. Predictors of Response to Radioligand Therapy of Metastatic Castrate-Resistant Prostate Cancer with 177Lu-PSMA-617. J. Nucl. Med. 2017, 58, 312-319. [CrossRef]

69. Emmett, L.; Crumbaker, M.; Ho, B.; Willowson, K.; Eu, P.; Ratnayake, L.; Epstein, R.; Blanksby, A.; Horvath, L.; Guminski, A.; et al. Results of a Prospective Phase 2 Pilot Trial of 177Lu-PSMA-617 Therapy for Metastatic Castration-Resistant Prostate Cancer Including Imaging Predictors of Treatment Response and Patterns of Progression. Clin. Genitourin. Cancer 2019, 17, 15-22. [CrossRef]

70. Eiber, M.; Herrmann, K.; Calais, J.; Hadaschik, B.; Giesel, F.L.; Hartenbach, M.; Hope, T.; Reiter, R.; Maurer, T.; Weber, W.A.; et al. Prostate Cancer Molecular Imaging Standardized Evaluation (PROMISE): Proposed miTNM Classification for the Interpretation of PSMA-Ligand PET/CT. J. Nucl. Med. 2018, 59, 469-478. [CrossRef]

71. Rowe, S.P.; Pienta, K.J.; Pomper, M.G.; Gorin, M.A. Proposal for a Structured Reporting System for Prostate-Specific Membrane Antigen-Targeted PET Imaging: PSMA-RADS Version 1.0. J. Nucl. Med. 2018, 59, 479-485. [CrossRef]

72. Ceci, F.; Herrmann, K.; Hadaschik, B.; Castellucci, P.; Fanti, S. Therapy assessment in prostate cancer using choline and PSMA PET/CT. Eur. J. Nucl. Med. Mol. Imaging 2017, 44, 78-83. [CrossRef] [PubMed]

73. Nickols, N.; Anand, A.; Johnsson, K.; Brynolfsson, J.; Borrelli, P.; Juarez, J.; Parikh, N.; Jafari, L.; Eiber, M.; Rettig, M.B. aPROMISE: A Novel Automated-PROMISE platform to Standardize Evaluation of Tumor Burden in (18)F-DCFPyL (PSMA) images of Veterans with Prostate Cancer. J. Nucl. Med. 2021. [CrossRef] [PubMed]

74. Haberkorn, U.; Giesel, F.; Morgenstern, A.; Kratochwil, C. The Future of Radioligand Therapy: Alpha, beta, or Both? J. Nucl. Med. 2017, 58, 1017-1018. [CrossRef] [PubMed]

75. Kassis, A.I. Therapeutic radionuclides: Biophysical and radiobiologic principles. Semin. Nucl. Med. 2008, 38, 358-366. [CrossRef]

76. Benesova, M.; Schafer, M.; Bauder-Wust, U.; Afshar-Oromieh, A.; Kratochwil, C.; Mier, W.; Haberkorn, U.; Kopka, K.; Eder, M. Preclinical Evaluation of a Tailor-Made DOTA-Conjugated PSMA Inhibitor with Optimized Linker Moiety for Imaging and Endoradiotherapy of Prostate Cancer. J. Nucl. Med. 2015, 56, 914-920. [CrossRef]

77. Weineisen, M.; Schottelius, M.; Simecek, J.; Baum, R.P.; Yildiz, A.; Beykan, S.; Kulkarni, H.R.; Lassmann, M.; Klette, I.; Eiber M.; et al. 68Ga- and 177Lu-Labeled PSMA I\&T: Optimization of a PSMA-Targeted Theranostic Concept and First Proof-of-Concept Human Studies. J. Nucl. Med. 2015, 56, 1169-1176. [CrossRef]

78. Schuchardt, C.; Zhang, J.; Kulkarni, H.R.; Chen, X.; Mueller, D.; Baum, R.P. Prostate-specific membrane antigen radioligand therapy using (177)Lu-PSMA I\&T and (177)Lu-PSMA-617 in patients with metastatic castration-resistant prostate cancer: Comparison of safety, biodistribution and dosimetry. J. Nucl. Med. 2021. [CrossRef]

79. Calopedos, R.J.S.; Chalasani, V.; Asher, R.; Emmett, L.; Woo, H.H. Lutetium-177-labelled anti-prostate-specific membrane antigen antibody and ligands for the treatment of metastatic castrate-resistant prostate cancer: A systematic review and meta-analysis. Prostate Cancer Prostatic Dis. 2017, 20, 352-360. [CrossRef]

80. Hofman, M.S.; Violet, J.; Hicks, R.J.; Ferdinandus, J.; Thang, S.P.; Akhurst, T.; Iravani, A.; Kong, G.; Ravi Kumar, A.; Murphy, D.G.; et al. [(177)Lu]-PSMA-617 radionuclide treatment in patients with metastatic castration-resistant prostate cancer (LuPSMA trial): A single-centre, single-arm, phase 2 study. Lancet Oncol. 2018, 19, 825-833. [CrossRef]

81. von Eyben, F.E.; Roviello, G.; Kiljunen, T.; Uprimny, C.; Virgolini, I.; Kairemo, K.; Joensuu, T. Third-line treatment and 177LuPSMA radioligand therapy of metastatic castration-resistant prostate cancer: A systematic review. Eur. J. Nucl. Med. Mol. Imaging 2018, 45, 496-508. [CrossRef]

82. Yadav, M.P.; Ballal, S.; Sahoo, R.K.; Dwivedi, S.N.; Bal, C. Radioligand Therapy With 177Lu-PSMA for Metastatic CastrationResistant Prostate Cancer: A Systematic Review and Meta-Analysis. Am. J. Roentgenol. 2019, 213, 275-285. [CrossRef]

83. Zhang, H.; Koumna, S.; Pouliot, F.; Beauregard, J.M.; Kolinsky, M. PSMA Theranostics: Current Landscape and Future Outlook. Cancers (Basel) 2021, 13, 4023. [CrossRef] [PubMed]

84. Ahmadzadehfar, H.; Schlolaut, S.; Fimmers, R.; Yordanova, A.; Hirzebruch, S.; Schlenkhoff, C.; Gaertner, F.C.; Awang, Z.H.; Hauser, S.; Essler, M. Predictors of overall survival in metastatic castration-resistant prostate cancer patients receiving [(177)Lu]LuPSMA-617 radioligand therapy. Oncotarget 2017, 8, 103108-103116. [CrossRef]

85. Ahmadzadehfar, H.; Wegen, S.; Yordanova, A.; Fimmers, R.; Kürpig, S.; Eppard, E.; Wei, X.; Schlenkhoff, C.; Hauser, S.; Essler, M. Overall survival and response pattern of castration-resistant metastatic prostate cancer to multiple cycles of radioligand therapy using [177Lu]Lu-PSMA-617. Eur. J. Nucl. Med. Mol. Imaging 2017, 44, 1448-1454. [CrossRef] [PubMed]

86. Bräuer, A.; Grubert, L.S.; Roll, W.; Schrader, A.J.; Schäfers, M.; Bögemann, M.; Rahbar, K. (177)Lu-PSMA-617 radioligand therapy and outcome in patients with metastasized castration-resistant prostate cancer. Eur. J. Nucl. Med. Mol. Imaging 2017, 44, 1663-1670. [CrossRef] 
87. Fendler, W.P.; Reinhardt, S.; Ilhan, H.; Delker, A.; Böning, G.; Gildehaus, F.J.; Stief, C.; Bartenstein, P.; Gratzke, C.; Lehner, S.; et al. Preliminary experience with dosimetry, response and patient reported outcome after 177 Lu-PSMA-617 therapy for metastatic castration-resistant prostate cancer. Oncotarget 2016, 8, 3581-3590. [CrossRef] [PubMed]

88. Kratochwil, C.; Giesel, F.L.; Stefanova, M.; Benešová, M.; Bronzel, M.; Afshar-Oromieh, A.; Mier, W.; Eder, M.; Kopka, K.; Haberkorn, U. PSMA-Targeted Radionuclide Therapy of Metastatic Castration-Resistant Prostate Cancer with ${ }^{177} \mathrm{Lu}-\mathrm{Labeled}$ PSMA-617. J. Nucl. Med. 2016, 57, 1170-1176. [CrossRef]

89. Rahbar, K.; Ahmadzadehfar, H.; Kratochwil, C.; Haberkorn, U.; Schäfers, M.; Essler, M.; Baum, R.P.; Kulkarni, H.R.; Schmidt, M.; Drzezga, A.; et al. German Multicenter Study Investigating ${ }^{177}$ Lu-PSMA-617 Radioligand Therapy in Advanced Prostate Cancer Patients. J. Nucl. Med. 2017, 58, 85-90. [CrossRef] [PubMed]

90. Rahbar, K.; Boegemann, M.; Yordanova, A.; Eveslage, M.; Schäfers, M.; Essler, M.; Ahmadzadehfar, H. PSMA targeted radioligandtherapy in metastatic castration resistant prostate cancer after chemotherapy, abiraterone and/or enzalutamide. A retrospective analysis of overall survival. Eur. J. Nucl. Med. Mol. Imaging 2018, 45, 12-19. [CrossRef] [PubMed]

91. Grubmüller, B.; Senn, D.; Kramer, G.; Baltzer, P.; D’Andrea, D.; Grubmüller, K.H.; Mitterhauser, M.; Eidherr, H.; Haug, A.R.; Wadsak, W.; et al. Response assessment using 68Ga-PSMA ligand PET in patients undergoing 177Lu-PSMA radioligand therapy for metastatic castration-resistant prostate cancer. Eur. J. Nucl. Med. Mol. Imaging 2019, 46, 1063-1072. [CrossRef]

92. Seifert, R.; Herrmann, K.; Kleesiek, J.; Schafers, M.; Shah, V.; Xu, Z.; Chabin, G.; Grbic, S.; Spottiswoode, B.; Rahbar, K. Semiautomatically Quantified Tumor Volume Using (68)Ga-PSMA-11 PET as a Biomarker for Survival in Patients with Advanced Prostate Cancer. J. Nucl. Med. 2020, 61, 1786-1792. [CrossRef]

93. Seifert, R.; Kessel, K.; Schlack, K.; Weber, M.; Herrmann, K.; Spanke, M.; Fendler, W.P.; Hadaschik, B.; Kleesiek, J.; Schäfers, M.; et al. PSMA PET total tumor volume predicts outcome of patients with advanced prostate cancer receiving [177Lu]Lu-PSMA-617 radioligand therapy in a bicentric analysis. Eur. J. Nucl. Med. Mol. Imaging 2021, 48, 1200-1210. [CrossRef] [PubMed]

94. Kratochwil, C.; Bruchertseifer, F.; Rathke, H.; Hohenfellner, M.; Giesel, F.L.; Haberkorn, U.; Morgenstern, A. Targeted alphaTherapy of Metastatic Castration-Resistant Prostate Cancer with (225)Ac-PSMA-617: Swimmer-Plot Analysis Suggests Efficacy Regarding Duration of Tumor Control. J. Nucl. Med. 2018, 59, 795-802. [CrossRef] [PubMed]

95. Sathekge, M.; Bruchertseifer, F.; Vorster, M.; Lawal, I.O.; Knoesen, O.; Mahapane, J.; Davis, C.; Reyneke, F.; Maes, A.; Kratochwil, C.; et al. Predictors of Overall and Disease-Free Survival in Metastatic Castration-Resistant Prostate Cancer Patients Receiving (225)Ac-PSMA-617 Radioligand Therapy. J. Nucl. Med. 2020, 61, 62-69. [CrossRef] [PubMed]

96. Yadav, M.P.; Ballal, S.; Sahoo, R.K.; Tripathi, M.; Seth, A.; Bal, C. Efficacy and safety of (225)Ac-PSMA-617 targeted alpha therapy in metastatic castration-resistant Prostate Cancer patients. Theranostics 2020, 10, 9364-9377. [CrossRef]

97. Feuerecker, B.; Tauber, R.; Knorr, K.; Heck, M.; Beheshti, A.; Seidl, C.; Bruchertseifer, F.; Pickhard, A.; Gafita, A.; Kratochwil, C.; et al. Activity and Adverse Events of Actinium-225-PSMA-617 in Advanced Metastatic Castration-resistant Prostate Cancer After Failure of Lutetium-177-PSMA. Eur. Urol. 2021, 79, 343-350. [CrossRef]

98. Robertson, A.K.H.; Ramogida, C.F.; Schaffer, P.; Radchenko, V. Development of (225)Ac Radiopharmaceuticals: TRIUMF Perspectives and Experiences. Curr. Radiopharm. 2018, 11, 156-172. [CrossRef] [PubMed] 